\title{
50 anos de residência médica do Departamento de Puericultura e Pediatria da Faculdade de Medicina de Ribeirão Preto da USP
}

\author{
50 years of pediatric residency training program of child \\ care and Pediatrics Department of School of Medicine \\ of Ribeirão Preto - University of São Paulo
}

Luiz Antonio Del Ciampo

\begin{abstract}
RESUMO
O artigo apresenta a trajetória de cinqüenta anos do Programa de Residência Médica do Departamento de Puericultura e Pediatria da Faculdade de Medicina de Ribeirão Preto da Universidade de São Paulo, que foi iniciado em 1957, destacando seus aspectos históricos, o número de vagas oferecidas e de médicos residentes que nele exerceram atividades, até o ano de 2006.
\end{abstract}

Palavras-chaves: Residência médica. Educação Médica. Pediatria.

O ano de 2006 marcou o cinqüentenário das atividades de residência médica do Departamento de Puericultura e Pediatria (DPP) da Faculdade de Medicina de Ribeirão Preto da Universidade de São Paulo (FMRPUSP). Esta trajetória foi iniciada em 1957, um ano após a criação do Departamento pelo Prof. Jacob Renato Woiski, então docente da Escola Paulista de Medicina e que foi para Ribeirão Preto a convite do Prof. Zeferino Vaz, para colaborar na estruturação da mais nova faculdade de medicina do país, a primeira do interior do estado de São Paulo, que iniciara suas atividades em $1952 .{ }^{1}$
Desde 1957 quando contou com a participação do primeiro residente que foi o Dr. Norberto de Oliveira Neto, médico formado pela Escola Paulista de Medicina da capital paulista, a residência médica no DPP expandiu-se rapidamente, chegando a totalizar, nesses cinqüenta anos, 2130 vagas que foram ocupadas por 976 médicos residentes, sendo 532 (54,5\%) mulheres e 444 (45,5\%) homens.

Para efeito de registro histórico, o ano de 1889 é a referência principal da residência médica, pois assinala quando o cirurgião norte-americano William Haldsted criou o primeiro programa de residência 
médica no Departamento de Cirurgia da Faculdade de Medicina da Universidade John's Hopkins. Já no ano seguinte, na mesma faculdade, William Osler implantou um programa semelhante no Departamento de Clínica Médica, consolidando essa nova área de treinamento em serviço para os médicos recém-formados. Em 1927 a Associação Médica Americana reconheceu a necessidade da residência médica como treinamento pós-graduado e elaborou uma relação de hospitais que atendiam às suas diretrizes e estavam capacitados a desenvolver programas de residência médica, consolidando definitivamente essa prática na formação médica. ${ }^{2,3}$

No Brasil, os primeiros programas de residência médica surgiram em 1945, no Hospital das Clínicas da Universidade de São Paulo e no Hospital dos Servidores do Estado do Rio de Janeiro. Desde então, a residência médica brasileira vem passando por diversas fases, sendo que a primeira delas transcorreu de 1945 ao final da década de 1950, e caracterizou-se por uma pequena procura por parte dos médicos, pois a grande maioria dos recém-formados iniciava sua vida profissional imediatamente após receber o diploma do curso médico e, portanto, havia poucos interessados na residência médica. Nesse período, o DPP teve apenas um médico residente de primeiro ano em 1957, dois em 1958 e um residente de segundo ano, em 1959.

A segunda fase da residência médica no Brasil durou quinze anos e caracterizou-se pela consolidação das atividades e dos programas e pelo aumento da procura por parte dos recém-formados. Acompanhando essa evolução histórica, a partir da década de 1960 , o DPP passou a oferecer aos egressos da FMRPUSP um ano de residência médica àqueles que estivessem interessados em seguir a carreira pediátrica, com atividades desenvolvidas no âmbito da Pediatria Geral, principalmente, e que mais tarde foram ampliadas para contemplar as novas áreas especializadas que começavam a ganhar destaque no contexto dos cuidados à saúde da criança e do adolescente. Destaque-se que entre 1957 e 1961 houve, no DPP, apenas um médico residente de segundo ano, em 1959. A partir de 1962 houve, ininterruptamente até agora, dois anos de residência médica completos.

No período de 1960 a 1975 foram preenchidas no DPP 180 vagas para médicos residentes de primeiro ano, 99 para segundo ano e 10 para terceiro ano.

O cenário da residência médica no Brasil começa a se modificar no início da década de 1970, ca- racterizando o início de uma nova fase, quando inicia a abertura de várias escolas médicas no país, o que acarretou uma rápida expansão da quantidade de serviços que ofereciam residência médica. Diante disso, e em função da necessidade de se implementar melhorias na qualidade do treinamento oferecido aos residentes, em 1976, foi criada a Comissão Nacional de Residência Médica cujo objetivo principal era o de estabelecer requisitos mínimos e normatizar as regras para o credenciamento e funcionamento de novos programas de residência médica. ${ }^{4,5}$ Naquele momento, diante inevitável ampliação das atividades desenvolvidas pelo Departamento de Puericultura e Pediatria e das necessidades de treinamento dos médicos recémformados, o DPP reorganizou seu Programa de Residência Médica e estabeleceu em vinte e quatro o número de vagas oferecidas para médicos residentes tanto do primeiro quanto para o segundo ano.

No período de 1976 a 2006 foram ocupadas, no DPP, 734 vagas de médicos residentes de primeiro ano, 722 de segundo ano e 378 de terceiro ano. A Tabela 1 apresenta a distribuição anual das 2130 vagas ocupadas por médicos residentes de primeiro, segundo e terceiro anos, do DPP, no período de 1957 a 2006.

A primeira vaga para médico residente de terceiro ano do DPP surgiu em 1964, sendo que no período de 1964 a 1969 apenas sete médicos (um em 1964, um em 1965, dois em 1966 e três em 1967) cumpriram três anos de residência médica em pediatria. Houve ainda um residente de terceiro ano em 1970 e dois em 1971, totalizando dez residentes nos primeiros vinte e um anos de atividades da residência médica do DPP. Após um período de seis anos, a partir de 1978, o número de residentes em atividades no terceiro ano aumentou gradativa e ininterruptamente, até atingir o total de 388 vagas ocupadas nesses cinqüenta anos.

A Tabela 2 apresenta a distribuição dos 976 médicos residentes do DPP de acordo com o tempo de permanência no programa de residência médica.

\section{Os egressos da FMRPUSP e a resi- dência médica no DPP}

Em 1957 a FMRPUSP formou sua primeira turma e entre os 43 diplomados daquele ano estavam os Drs. João Romera e Keiko Marafuji, que seriam os primeiros médicos formados em Ribeirão Preto a ingressarem na residência médica do DPP, sendo que o Dr. João Romera foi o primeiro residente a cumprir dois anos de atividades na residência médica de pedi- 


\section{Tabela 1}

Distribuição das vagas para médicos residentes do DPP, 1957-2006

\begin{tabular}{|c|c|c|c|c|c|c|c|}
\hline Ano & $\mathrm{R} 1$ & $\mathrm{R} 2$ & R3 & Ano & $\mathrm{R} 1$ & $\mathrm{R} 2$ & R3 \\
\hline 1957 & 1 & & & 82 & 24 & 24 & 9 \\
\hline 58 & 2 & & & 83 & 24 & 24 & 10 \\
\hline 59 & & 1 & & 84 & 20 & 24 & 12 \\
\hline 1960 & 3 & & & 85 & 20 & 21 & 11 \\
\hline 61 & 6 & & & 86 & 24 & 20 & 8 \\
\hline 62 & 5 & & & 87 & 25 & 24 & 10 \\
\hline 63 & 8 & 2 & & 88 & 24 & 23 & 2 \\
\hline 64 & 7 & 6 & 1 & 89 & 24 & 25 & 11 \\
\hline 65 & 11 & 4 & 1 & 1990 & 24 & 25 & 12 \\
\hline 66 & 9 & 3 & 2 & 91 & 24 & 25 & 13 \\
\hline 67 & 11 & 4 & 3 & 92 & 24 & 23 & 15 \\
\hline 68 & 12 & 7 & & 93 & 24 & 24 & 11 \\
\hline 69 & 14 & 8 & & 94 & 24 & 23 & 17 \\
\hline 1970 & 12 & 10 & 1 & 95 & 24 & 22 & 21 \\
\hline 71 & 10 & 5 & 2 & 96 & 24 & 23 & 17 \\
\hline 72 & 12 & 8 & & 97 & 24 & 23 & 15 \\
\hline 73 & 16 & 9 & & 98 & 24 & 21 & 17 \\
\hline 74 & 24 & 13 & & 99 & 24 & 24 & 18 \\
\hline 75 & 20 & 20 & & 2000 & 24 & 23 & 21 \\
\hline 76 & 24 & 24 & & 01 & 24 & 22 & 24 \\
\hline 77 & 24 & 26 & & 02 & 24 & 24 & 22 \\
\hline 78 & 24 & 22 & 1 & 03 & 24 & 24 & 14 \\
\hline 79 & 24 & 24 & 3 & 04 & 24 & 22 & 18 \\
\hline 1980 & 25 & 24 & 2 & 05 & 24 & 24 & 24 \\
\hline 81 & 24 & 23 & 3 & 06 & 21 & 24 & 17 \\
\hline
\end{tabular}

Tabela 2

Distribuição dos 976 médicos residentes do DPP segundo o tempo de atividades no programa de residência médica

\begin{tabular}{lrr}
\hline Anos de atividade & $\mathrm{n}$ & $\%$ \\
\hline 1 ano (R1) & 115 & 11,8 \\
1 ano (R2) & 18 & 1,8 \\
1 ano (R3) & 38 & 3,9 \\
2 anos (R1 + R2) & 475 & 48,6 \\
2 anos (R2 + R3) & 6 & 0,6 \\
3 anos (R1 + R2 + R3) & 324 & 33,2 \\
\hline Total & 976 & 100 \\
\hline
\end{tabular}

atria, nos anos de 1958 e 19591. Nos primeiros cinquienta anos de atividades no DPP, as 918 vagas de residentes de primeiro ano foram ocupadas na seguinte proporção: 524 (57\%) médicos formados na FMRPUSP e $394(43 \%)$ oriundos de outras faculdades de medicina de diversos pontos do país. A Tabela 3 apresenta a distribuição das vagas de médicos residentes de primeiro ano ocupadas por egressos da FMRPUSP.

Observa-se que até o final da década de 1980 a maior parte das vagas do Programa de Residência Médica era ocupada por médicos egressos da FMRPUSP, fato que foi modificando-se a partir da década de 1990, acompanhando uma tendência observada em outras faculdades de medicina, de redu- 


\section{Tabela 3}

Distribuição da proporção do número de vagas no primeiro ano para médicos residentes no DPP, ocupadas por egressos da FMRPUSP

\begin{tabular}{|c|c|c|c|c|c|}
\hline Ano & $\begin{array}{c}\text { Egressos } \\
\text { FMRP/ vagas }\end{array}$ & $\%$ & Ano & $\begin{array}{c}\text { Egressos } \\
\text { FMRP/ vagas }\end{array}$ & $\%$ \\
\hline 1957 & $0 / 1$ & 0 & 82 & $11 / 24$ & 45,8 \\
\hline 58 & $2 / 2$ & 100 & 83 & $16 / 24$ & 66,6 \\
\hline 59 & $1 / 1$ & 100 & 84 & $15 / 20$ & 75,0 \\
\hline 1960 & $2 / 3$ & 66,6 & 85 & $15 / 20$ & 75,0 \\
\hline 61 & $4 / 6$ & 66,6 & 86 & $18 / 24$ & 75,0 \\
\hline 62 & $4 / 5$ & 80,0 & 87 & $15 / 25$ & 60,0 \\
\hline 63 & $8 / 8$ & 100 & 88 & $14 / 24$ & 58,3 \\
\hline 64 & $6 / 7$ & 85,7 & 89 & $9 / 24$ & 37,5 \\
\hline 65 & 9/11 & 81,8 & 1990 & $15 / 24$ & 62,5 \\
\hline 66 & $8 / 9$ & 88,8 & 91 & $9 / 24$ & 37,5 \\
\hline 67 & $7 / 11$ & 63,6 & 92 & $8 / 24$ & 33,3 \\
\hline 68 & $8 / 12$ & 66,6 & 93 & $14 / 24$ & 58,3 \\
\hline 69 & $11 / 14$ & 78,5 & 94 & $12 / 24$ & 50,0 \\
\hline 1970 & $11 / 12$ & 91,6 & 95 & $8 / 24$ & 33,3 \\
\hline 71 & $10 / 10$ & 100 & 96 & $12 / 24$ & 50,0 \\
\hline 72 & $12 / 12$ & 100 & 97 & $14 / 24$ & 58,3 \\
\hline 73 & $15 / 16$ & 93,7 & 98 & $6 / 24$ & 25,0 \\
\hline 74 & $20 / 24$ & 83,3 & 99 & $6 / 24$ & 25,0 \\
\hline 75 & $20 / 20$ & 100,0 & 2000 & $10 / 24$ & 41,6 \\
\hline 76 & $22 / 24$ & 91,6 & 01 & $3 / 24$ & 12,5 \\
\hline 77 & $15 / 24$ & 62,5 & 02 & $4 / 24$ & 16,6 \\
\hline 78 & $22 / 24$ & 91,6 & 03 & $4 / 24$ & 16,6 \\
\hline 79 & $16 / 24$ & 66,6 & 04 & $3 / 24$ & 12,5 \\
\hline 1980 & $24 / 25$ & 96,0 & 05 & $0 / 24$ & 0,00 \\
\hline 81 & $22 / 24$ & 91,6 & 06 & $3 / 20$ & 15,0 \\
\hline
\end{tabular}

ção na procura por Residência Médica em Pediatria, visto que o país passou a contar com um grande número de pediatras e que o mercado profissional acenava com mais atrativos para outras especialidades médicas.

Decorrido meio século, o Programa de Residência Médica do DPP, que se iniciou em 1957 com apenas um médico residente exercendo atividades nas enfermarias e ambulatório do Hospital das Clínicas situado nos altos da cidade de Ribeirão Preto, hoje denominado Unidade de Emergência do Hospital das Clínicas, evoluiu para, em 2006, contar com 59 médicos residentes em treinamento, cujas atividades estão distribuídas nas diferentes unidades de atendimento à saúde da criança e do adolescente que envolve a participação do DPP. Desde sua criação, o DPP tem de- 
senvolvido atividades de ensino, assistência, pesquisa e extensão em todos os níveis, congregando alunos, docentes, médicos residentes, médicos assistentes e estagiários, sendo um dos departamentos pioneiros da FMRPUSP a criar e a inserir-se em atividades em níveis primário (Centro Médico Social Comunitário Vila Lobato, Centro Médico Social Comunitário de Pradópolis, Centro de Saúde Escola da FMRPUSP e Centro de Saúde do Ipiranga). Também nos níveis de atenção secundário e terciário (ambulatório e enfermarias da Unidade de Emergência do HCFMRPUSP, Berçários, ambulatórios e enfermarias especializados do HC Campus, Centros de Terapia Intensiva na Unidade de Emergência e no Campus e Berçário da Mater) destaca-se o DPP em oferecer treinamento especializado aos médicos residentes, sendo que todos os serviços contam com apoio de médicos assistentes e funcionam sob a supervisão de docentes. ${ }^{6}$

\section{ABSTRACT}

The article presents the history of fifty years of the Pediatric Residency Training Program of Child Care and Pediatrics Department of School of Medicine of Ribeirão Preto of University of São Paulo, started in 1957, highlighting historical aspects, the number of places offered and the residents who have lawfully pursued activities by the year 2006.

Keywords: Residency, Medical. Education, Medical. Pediatrics.

\section{Referênclas Blbllográficas}

1. Santoro JR, Gonçalves AL. Os 50 anos do Departamento de Puericultura e Pediatria da Faculdade de Medicina de Ribeirão Preto, da Universidade de São Paulo. Mimeo

2. Martins LAN. Residência médica. Estresse e crescimento. São Paulo: Casa do Psicólogo; 2005.

3. Lima-Gonçalves E. Médicos e ensino da medicina no Brasil. São Paulo: Edusp; 2002.
4. Sousa EG. Consideração sobre a residência médica no Brasil. Rev Bras Colo-Proct. 1988;8:150-2.

5. Bacheschi LA. A residência médica. In: Marcondes E, LimaGonçalves E. editores. Educação Médica. São Paulo: Sarvier;1998. p. 369-73.

6. Del Ciampo LA, Galvão LC, Carlotti APPC, Ferraz IS. Avaliação de médicos residentes em um programa de residência médica em Puericultura e Pediatria. Bol Assoc Bras Educ Med. 2004; 32: 11-13. 